\title{
Açaí (Euterpe oleracea Mart) Consumption and Prevention of Chronic Diseases: Is There an Association? A Preliminary Study
}

\author{
Dulcelena Ferreira Silva, ${ }^{1}$ Marcos Antonio Custódio Neto da Silva, \\ Gabrielle Meirelles Rodrigues, ${ }^{3}$ Flávia Castello Branco Vidal, ${ }^{4}$ \\ Maria do Carmo Lacerda Barbosa, ${ }^{5}$ Luciane Maria Oliveira Brito $\left(\mathbb{D},{ }^{6}\right.$ \\ Geusa Felipa de Barros Bezerra, ${ }^{7}$ Walbert Edson Muniz Filho, ${ }^{8}$ \\ Kátia Regina Assunção Borges, ${ }^{3}$ Ivone Garros Rosa, ${ }^{9}$ João Ernesto de Carvalho, ${ }^{10}$ \\ and Maria do Desterro Soares Brandão Nascimento ${ }^{7}{ }^{7}$ \\ ${ }^{1}$ Morphology Department, Federal University of Maranhão, São Luiis, Maranhão, Brazil \\ ${ }^{2}$ Post-Graduate Program in Internal Medicine, Medical Science School, State University of Campinas, Campinas, \\ São Paulo, Brazil \\ ${ }^{3}$ Federal University of Maranhão, São Luiis, Maranhão, Brazil \\ ${ }^{4}$ Morphology Department, Post-Graduate Program in Adult Health, Federal University of Maranhão, São Luiis, Maranhão, Brazil \\ ${ }^{5}$ Medicine I Department, Federal University of Maranhão, São Luiis, Maranhão, Brazil \\ ${ }^{6}$ Medicine III Department, Post-Graduate Program in Adult Health, Federal University of Maranhão, São Luiis, \\ Maranhão, Brazil \\ ${ }^{7}$ Pathology Department, Post-Graduate Program in Adult Health, Federal University of Maranhão, São Luiis, Maranhão, Brazil \\ ${ }^{8}$ Pathology Department, Federal University of Maranhão, São Luiis, Maranhão, Brazil \\ ${ }^{9}$ Pathology Department, Health and Environment Post-Graduate Program, Federal University of Maranhão, São Luiis, \\ Maranhão, Brazil \\ ${ }^{10}$ Pharmaceutic Science School, Post-Graduate Program in Internal Medicine, State University of Campinas, Campinas, \\ São Paulo, Brazil
}

Correspondence should be addressed to Maria do Desterro Soares Brandão Nascimento; cnsd_ma@uol.com.br

Received 17 December 2019; Revised 7 April 2020; Accepted 9 May 2020; Published 1 June 2020

Academic Editor: Elisabetta Baldi

Copyright ( $\odot 2020$ Dulcelena Ferreira Silva et al. This is an open access article distributed under the Creative Commons Attribution License, which permits unrestricted use, distribution, and reproduction in any medium, provided the original work is properly cited.

Background. Flavonoids from a variety of fruits, including açaí, have beneficial antioxidant activity in several diseases, including cancer. Breast cancer is the second most prevalent cancer among Brazilian women. Studies have shown the action of flavonoids on neoplastic cells, as well as on diabetes and neurodegenerative and cardiovascular diseases. Objective. To analyze the relationship between the consumption of açaí and the presence of chronic diseases in women residing in the rural area of São Luís, Maranhão. Methods. A convenience sample of 150 women residing in the Maracanã neighborhood in São Luís, Maranhão, was used; the collected data included sociodemographic characteristics, habits, sexual and reproductive history, consumption of açaí, and history of cancer and other chronic diseases. The sample was divided into women who consumed açaí at least once a week (cases) and women who did not consume açaí (controls). Statistical analysis was performed to assess the relationships between those variables and the consumption of açaí. Results. A total of 141 women (94\%) consumed açaí. Among these, 79.3\% were aged between 20 and 50 years, 78.67\% were farmers or housewives, $64.67 \%$ were Pardo (mixed race), $76.67 \%$ were nonsmokers, $70 \%$ were not receiving hormonal therapy, $40.67 \%$ had already undergone mammography, $28 \%$ had already undergone breast ultrasound, and $27.33 \%$ had a family history of cancer, with breast cancer being the second most prevalent cancer. There was a higher prevalence of hypertension among women who did not consume açaí than that among those who did; however, previous cancer, family history of cancer, heart disease, and diabetes were more prevalent among the consumers of açaí. There were no statistically significant relationships. Conclusion. Flavonoids are known to have a beneficial effect on some types of neoplastic cells and other diseases; therefore, larger studies are necessary to better evaluate the beneficial effects of consuming foods containing flavonoids on these diseases. 


\section{Introduction}

Açaí (Euterpe oleracea Mart.) is a typical and popular fruit of the Amazon region that has gained importance in recent years because of its health benefits, which are associated with its phytochemical composition and antioxidant capacity [1]. It is primarily found in states of the Northern region of Brazil. The state of Pará is the largest producer of açaí, followed by the states of Maranhão, Amapá, Acre, and Rondônia [2].

Samples of açaí have been studied and shown to contain cyanidin-3-glucoside, cyanidin-3 sambubioside, cyanidin-3rutinoside, and peonidin 3-rutinoside. Açaí has a high concentration of anthocyanins ( $1.02 \mathrm{~g} / 100 \mathrm{~g}$ of dry solids), whose content in fruits is related to the prevention and reduction in the risk of cancer and cardiovascular and circulatory diseases through the scavenging of free radicals [3].

Experimental studies with transgenic mice and models of cancer mediated by carcinogens such as radiation and agents derived from exogenous or endogenous sources have shown that some phytochemicals consumed in the diet have a protective effect against cancer. This protection provided by dietary phytochemicals is the result of the induction of cellular defense mechanisms, including antioxidants, detoxification, activation of anti-inflammatory enzymes, and signaling pathways that lead to cell cycle arrest and/or cell death [4].

Cancer is a growing health problem worldwide, resulting from the increase in life expectancy and urbanization and subsequent changes to the environment [5]. Breast cancer is the most common type of cancer among women in Brazil and worldwide, after nonmelanoma skin cancer, with approximately 57,960 new cases $(28.1 \%)$ and an incidence of 56.2 cases per 1,000 people in 2016 [6].

Cancer-preventing phytochemicals, especially flavonoids, have been shown to suppress or prevent the progression of cancer by a variety of mechanisms. The intake of some types of flavonoids may contribute to the prevention of breast cancer [7], and a potent chemopreventive agent from the açaí extract has been shown in experimental studies to be useful in estrogen-dependent breast cancer treatment (Euterpe oleracea Mart.) [5].

Plants contain natural compounds with important bioactive properties, which might be alternatives to the currently used medications and lead to the discovery of new drugs $[8,9]$. The consumption of açaí is associated with the prevention and reduction in the risk of developing cancer and cardiovascular and circulatory diseases, in addition to the promotion of healthy aging and reduction of oxidative damage [10].

Thus, the objective of the present study was to analyze the relationship between the consumption of the açaí fruit and the presence of chronic diseases in women residing in the rural area of São Luís, Maranhão.

\section{Methods}

2.1. Study Type and Area. This cross-sectional, retrospective, and analytical study assessed the prevalence of açaí intake among women in São Luís, Maranhão, and its association with chronic diseases.
The study was conducted in the municipality of São Luís among women residing in the Maracanã Ecological Park, an Environmentally Protected Area (EPA), in which the Juçara Park is located [11].

2.2. Study Population. The population selected for this study was a convenience sample with a calculated sample size of 150 individuals aged between 12 and 80 years. The study period was between November 2014 and February 2015.

The inclusion criteria were women who resided in the Maracanã Ecological Park who provided their informed consent for their inclusion in the study.

The exclusion criteria included women residing in the Maracanã Ecological Park with mental impairments that could hinder their understanding of the questions on the specific questionnaire and women who refused to provide their informed consent.

2.3. Sample. The sample was composed of 141 women residing in the Maracanã Ecological Park who consumed açaí at least once a week (cases) and nine women who did not consume açaí (controls).

2.4. Data Collection. Data collection was performed between November 2014 and February 2015.

Interviews were conducted using a structured epidemiological questionnaire that included information on sociodemographic characteristics, habits, sexual and reproductive history, consumption of açaí, and history of cancer.

2.5. Statistical Analysis. The data were entered into an electronic database and analyzed using Stata/SE 9.0 for Windows (Stata Corporation, College Station, Texas, USA). The categorical variables were expressed as absolute and percentage values and the numerical variables as means and standard deviations.

Chi-square test or Fisher's exact test was used to assess the relationship between categorical variables, and two-sided $t$-tests were used for comparison of numerical variables (age).

In all tests, the significance level $(\alpha)$ was set at $5 \%$; i.e., the results were considered significant for $p<0.05$.

2.6. Ethical Considerations. This study was submitted to and approved by the Research Ethics Committee of the University Hospital of the Federal University of Maranhão (number 814.669/2014). The women included in the study provided their informed consent (resolution 466/12 of the National Health Council and its complementary resolutions).

\section{Results}

The study included 150 women, of which $0.67 \%$ (1/150) were less than 20, 25.33\% (38/150) were between 20 and 30 , $33.33 \%$ (50/150) were between 31 and 40, 15020.67\% (31/ 
$150)$ were between 41 and 50, 10.67\% (16/150) were between 51 and $60,6.00 \%(9 / 150)$ were between 61 and 70 , and 3.33\% $(5 / 150)$ were between 71 and 80 years of age. The patients' ages ranged between 12 and 80 years (mean age of 40.49 years, $\mathrm{SD} \pm 13.23)$. There was no statistically significant difference in age between the group that consumed açaí (141 women) and the control group (9 women). With regard to years of schooling, $6.67 \%(10 / 150)$ were illiterate women and $9.34 \%(14 / 150), 27.33 \%(41 / 150), 43.33 \%(65 / 150)$, and $12.67 \%(19 / 150)$ of women had studied for 1 to 3,4 to 7,8 to 11 , and more than 11 years, respectively. With regard to occupation, $40.67 \%$ (70/150) were housewives, 32\% (48/150) were farmers, $14.67 \%$ (22/150) were merchants, $4.66 \%$ (7/ $150)$ were retired, and $2.00 \%(3 / 150)$ were students. The distributions according to marital status were as follows: $36.67 \%$ (55/150) were single; $32.67 \%$ (49/150) were married; $22.00 \%(33 / 150)$ lived in cohabitation, $6.66 \%(10 / 150)$ were widows, and $2.00 \%(3 / 150)$ were separated. With regard to ethnicity, 64.67\% (97/150) were Pardo Brazilian, 20.67\% (31/ 150) were Afro-Brazilian, $13.33 \%$ (20/150) were White Brazilian, $0.67 \%(1 / 150)$ were indigenous, and $0.66 \%(1 / 150)$ were Asian Brazilian. The analysis of family income showed that $15.34 \%(23 / 150)$ received half of the minimum salary per month, $48.00 \%(72 / 150)$ received one minimum salary per month, $21.33 \%(32 / 150)$ received two minimum salaries per month, $0-67 \%(1 / 150)$ received three minimum salaries per month, $11.33 \%$ (17/150) received more than three minimum salaries per month, and 3.33\% (5/150) did not answer (Table 1).

Most women were nonsmokers $(76.67 \% ; 115 / 150)$ and $6.00 \%(9 / 150)$ were former smokers; however, most of the former and current smokers ( 35 women) had been or were smokers for 10 years or more $(57.15 \% ; 20 / 35)$. In the sample, $54.67 \%(82 / 150)$ of women were not alcoholics, $42.00 \%$ (63/ $150)$ consumed alcoholic beverages, and $3.33 \%$ (5/150) were former alcoholics (Table 1).

With regard to açaí intake, $94.00 \%$ (141/150) consumed the fruit at least once a week and $6.00 \%(9 / 150)$ did not consume it. The majority of those who consumed açaí $(77.30 \% ; 109 / 141)$ had been consuming it for more than 10 years, $51.77 \%(73 / 141)$ consumed açaí at least three times a week, and $86.52 \%(122 / 141)$ consumed it in the form of juice (Table 2).

With regard to reproductive characteristics, the majority of women $(70.00 \% ; 105 / 150)$ had attained menarche between 11 and 14 years of age and had not yet entered menopause $(76.00 \%$; 114/150). Moreover, $89.33 \%$ (134/150) had been pregnant, with the majority $(52.00 \% ; 78 / 150)$ having had two to four full-term pregnancies, $91.33 \%$ (137/ 150) had not had preterm pregnancies, $83.33 \%(125 / 150)$ never had an abortion, and $82.67 \%(124 / 150)$ had breastfed (Table 3). Hormonal therapy was not used by $70.00 \%$ (105/ 150) of the women, and most women who reported using hormonal therapy $(57.78 \%$; $26 / 45)$ used oral contraceptives only. Most women $(88.67 \%$; $133 / 150)$ did not have a history of breast trauma.

In the sample, $40.67 \%(61 / 150)$ of the women had undergone mammography, with $50.82 \%$ of these (31/61) having undergone an exam approximately one year before,
TABLE 1: Sociodemographic characteristics of women residing in the Maracanã neighborhood, São Luís, MA.

\begin{tabular}{|c|c|c|c|}
\hline \multirow{2}{*}{ Variables } & \multicolumn{2}{|c|}{ Açaí consumption } & \multirow[b]{2}{*}{$p$} \\
\hline & No $f(\%)$ & Yes $f(\%)$ & \\
\hline \multicolumn{3}{|l|}{ Years of schooling } & \multirow{7}{*}{0.39} \\
\hline Illiterate & $2(22.22)$ & $8(5.67)$ & \\
\hline $1-3$ & $0(0.00)$ & $13(9.22)$ & \\
\hline $4-7$ & $3(33.33)$ & $39(27.66)$ & \\
\hline $8-11$ & $2(22.22)$ & $63(44.68)$ & \\
\hline More than 11 & $2(22.22)$ & $17(12.06)$ & \\
\hline Not informed & $0(0.00)$ & $1(0.71)$ & \\
\hline \multicolumn{3}{|l|}{ Occupation } & \multirow{6}{*}{0.17} \\
\hline Housewife & $5(55.56)$ & $65(46.10)$ & \\
\hline Farmer & $1(11.11)$ & $47(33.33)$ & \\
\hline Merchant & $1(11.11)$ & $21(14.89)$ & \\
\hline Retired & $1(11.11)$ & $6(4.26)$ & \\
\hline Student & $1(11.11)$ & $2(1.42)$ & \\
\hline \multicolumn{3}{|l|}{ Marital status } & \multirow{6}{*}{0.27} \\
\hline Single & $4(44.44)$ & $51(36.67)$ & \\
\hline Married & $2(22.22)$ & $47(33.33)$ & \\
\hline Stable union & $2(22.22)$ & $31(21.99)$ & \\
\hline Widow & $0(0.00)$ & $10(7.09)$ & \\
\hline Separated & $1(11.11)$ & $2(1.42)$ & \\
\hline \multicolumn{3}{|l|}{ Ethnicity } & \multirow{6}{*}{0.99} \\
\hline Asian race & $0(0.00)$ & $1(0.71)$ & \\
\hline Caucasian & $1(11.11)$ & $19(13.48)$ & \\
\hline Black & $2(22.22)$ & $29(20.57)$ & \\
\hline Pardo & $6(66.67)$ & $91(64.54)$ & \\
\hline Indigenous & $0(0.00)$ & $1(0.71)$ & \\
\hline \multicolumn{3}{|l|}{ Income } & \multirow{7}{*}{0.60} \\
\hline $1 / 2$ salary & $3(33.33)$ & $20(14.18)$ & \\
\hline 1 salary & $4(4.44)$ & $68(48.23)$ & \\
\hline 2 salaries & $1(11.11)$ & $31(21.99)$ & \\
\hline 3 salaries & $0(0.00)$ & $1(0.71)$ & \\
\hline More than 3 salaries & $0(0.00)$ & $17(12.06)$ & \\
\hline Not stated & $1(11.11)$ & $4(2.84)$ & \\
\hline \multicolumn{3}{|l|}{ Smoking } & \multirow{4}{*}{0.72} \\
\hline Yes & $1(11.11)$ & $25(17.73)$ & \\
\hline No & $7(77.78)$ & $108(76.60)$ & \\
\hline Former smoker & $1(11.11)$ & $8(5.67)$ & \\
\hline \multicolumn{3}{|l|}{ Alcoholism } & \multirow{4}{*}{0.38} \\
\hline Yes & $4(44.44)$ & $59(41.84)$ & \\
\hline No & $4(44.44)$ & $78(55.32)$ & \\
\hline Former alcoholic & $1(11.11)$ & $4(2.84)$ & \\
\hline
\end{tabular}

$39.34 \%(24 / 61)$ having undergone an exam two or more years before, and $9.84 \%(6 / 61)$ not knowing when they had undergone an exam. The diagnostic result was Category I for most of these women $(59.01 \%$; 36/61). Most women $(72.00 \% ; 108 / 150)$ had not undergone a breast ultrasound. Among those who had, most $(54.76 \% ; 23 / 42)$ had undergone an exam approximately one year before, 35.71\% (15/ 42 ) had undergone an exam two or more years before, and $9.52 \%(4 / 42)$ did not answer. Most women $(85.71 \% ; 36 / 42)$ had a Category I result. The results of the diagnostic exams were subjected to statistical analysis for correlation with açaí intake, with no statistically significant correlations (Table 4).

The assessment of comorbidities showed that $13.33 \%$ $(20 / 150)$ of the women were diabetic, $6.67 \%(10 / 150)$ had 
TABle 2: Lifestyle habits (açaí consumption, smoking, and alcoholism) among women who consumed açaí at least once a week.

\begin{tabular}{lcc}
\hline Variables & $N$ & $\%$ \\
\hline Years of consumption & 7 & \\
Up to 10 years & 109 & 4.66 \\
>10 years & 25 & 72.67 \\
Not stated & 9 & 16.67 \\
No & & 6.00 \\
\hline Form of consumption & 122 & \\
Juice & 19 & 81.33 \\
Pulp & 6 & 12.67 \\
Ice cream & 9 & 4.00 \\
No & & 6.00 \\
\hline Weekly frequency & 42 & \\
Once & 19 & 28.00 \\
Twice & 13 & 12.67 \\
Thrice & 60 & 8.67 \\
More than three times & 7 & 4.00 \\
Not stated & 9 & 6.00 \\
No &
\end{tabular}

${ }^{*}$ In this category, the participants were allowed to provide more than one answer.

TABLE 3: Relationship between the reproductive characteristics and açaí consumption among women residing in the Maracanã neighborhood, São Luís, MA.

\begin{tabular}{|c|c|c|c|}
\hline \multirow{2}{*}{ Variables } & \multicolumn{2}{|c|}{ Açaí consumption } & \multirow[b]{2}{*}{$p$} \\
\hline & No $f(\%)$ & Yes $f(\%)$ & \\
\hline \multicolumn{4}{|l|}{ Age at menarche* } \\
\hline 10 years & $0(0.00)$ & $5(3.55)$ & \multirow{5}{*}{0.88} \\
\hline $11-14$ years & $8(88.89)$ & $97(68.80)$ & \\
\hline More than 14 years & $1(11.11)$ & $36(25.53)$ & \\
\hline Not stated & $0(0.00)$ & $2(1.42)$ & \\
\hline No & $0(0.00)$ & $1(0.71)$ & \\
\hline \multicolumn{3}{|l|}{ Age at menopause* } & \multirow{6}{*}{0.60} \\
\hline 30 years & $0(0.00)$ & $1(0.71)$ & \\
\hline 35 years & $0(0.00)$ & $3(2.13)$ & \\
\hline 36 to 45 years & $0(0.00)$ & $10(7.09)$ & \\
\hline Older than 45 years & $3(33.33)$ & $19(13.48)$ & \\
\hline No & $6(66.67)$ & $108(76.60)$ & \\
\hline \multicolumn{3}{|l|}{ Full-term pregnancies* } & \multirow{5}{*}{0.63} \\
\hline 1 & $1(11.11)$ & $20(14.18)$ & \\
\hline $2-4$ & $3(33.33)$ & $75(53.19)$ & \\
\hline More than 4 & $2(22.22)$ & $27(19.15)$ & \\
\hline No & $3(33.33)$ & $19(13.48)$ & \\
\hline \multicolumn{3}{|l|}{ Preterm pregnancies** } & \multirow{3}{*}{0.60} \\
\hline 1 & $0(0.00)$ & $13(9.22)$ & \\
\hline No & $9(100.00)$ & $128(90.78)$ & \\
\hline \multicolumn{3}{|l|}{ Number of abortions ${ }^{*}$} & \multirow{6}{*}{0.99} \\
\hline 1 & $1(11.11)$ & $20(14.18)$ & \\
\hline 2 & $0(0.00)$ & $2(1.42)$ & \\
\hline 3 & $0(0.00)$ & $1(0.71)$ & \\
\hline 4 & $0(0.00)$ & $1(0.71)$ & \\
\hline No & $8(88.89)$ & $117(82.98)$ & \\
\hline \multicolumn{3}{|l|}{ Breastfeeding** } & \multirow{3}{*}{0.19} \\
\hline No & $3(33.33)$ & $23(16.31)$ & \\
\hline Yes & $6(66.67)$ & $118(83.69)$ & \\
\hline
\end{tabular}

${ }^{*}$ Chi-square test. ${ }^{* *}$ Fisher's exact test. heart disease, and $22.67 \%$ (34/150) were hypertensive. Statistical analysis revealed no statistically significant relationships between açaí consumption and the analyzed parameters (Table 5).

History of cancer revealed that $1.33 \%(2 / 150)$ had had cancer previously and the remaining women $(98.67 \%$; $148 /$ $150)$ had not and that $7.33 \%(11 / 150)$ had breast nodules. With regard to a family history of cancer, $27.33 \%(41 / 150)$ had cancer in the family. Of these, $31.71 \%(13 / 41)$ had a history of cancer in first-degree relatives (mother, father, and siblings), whereas $68.29 \%(28 / 41)$ had a history of cancer in second-degree relatives (uncles, grandparents, and cousins). The types of cancer in the family history included uterine $(31.7 \% ; 13 / 41)$, breast $(26.83 \% ; 11 / 41)$, ovarian $(9.75 \% ; 4 / 41)$, stomach, liver, bowel, prostate and penis cancers (each accounting for $4.88 \% ; 2 / 41$ ), and bone and lung cancers (each accounting for $2.44 \%$; $1 / 41$ ). One participant $(2.44 \%$; $1 / 41$ ) did not answer this item. There were no statistically significant relationships between a previous history of cancer, presence of breast nodules, and family history of breast cancer and other types of cancer and açaí consumption (Table 5).

\section{Discussion}

Diets rich in fruits and vegetables have been reported to increase the antioxidant capacity of plasma. In addition to containing vitamins $\mathrm{C}$ and $\mathrm{E}$ and beta-carotene, these foods contain phenolic compounds with antioxidant properties [12]. Dietary flavonoids are a large family of bioactive phenolic compounds that occur naturally in plant-based foods and are present in significant amounts in several fruits, vegetables, grains, herbs, and commonly consumed drinks [13].

Euterpe oleracea Mart. is a monocotyledonous species indigenous of the floodplain forests of the Amazon region, particularly in Venezuela, Colombia, Ecuador, The Guianas, Suriname, and Brazil (mainly in the states of Amazonas, Amapá, Pará, Maranhão, Rondônia, Acre, and Tocantins). It is known by the population as açaí, "açaai do pará," "açaí do baixo amazonas," "açái de touceira," "açái de planta," "juçara," and "juçara de touceira" $[14,15]$. The two latter designations are fairly common in the state of Maranhão.

The fruit has a rounded shape, a purplish-black color, is approximately $25 \mathrm{~mm}$ in diameter, and contains only one large seed. The analysis of the phenolic compounds in açaí showed the presence of anthocyanin 3-glucoside, ferulic acid, epicatechin, p-hydroxybenzoic acid, gallic acid, protocatechuic acid, catechin, ellagic acid, vanillic acid, p-coumaric acid, and gallotannin [12].

The intake of fruits and vegetables has been associated with a reduction in the risk of cancer in humans, particularly breast cancer. Dietary flavonoids, a group comprising more than 5,000 different polyphenolic compounds, have been identified as components of fruits and vegetables with the potential to prevent cancer [16]. 
TABLE 4: Relationship between the results of mammography and breast ultrasound and açaí consumption among women residing in the Maracanã neighborhood, São Luís, MA.

\begin{tabular}{lccc}
\hline \multirow{2}{*}{ Variables } & \multicolumn{2}{c}{ Açaí consumption } & p \\
& No $f(\%)$ & Yes $f(\%)$ & \\
\hline Mammography* & & & \\
Category I & $2(22.22)$ & $34(24.11)$ & \\
Category II & $0(0.00)$ & $2(1.42)$ & 0.20 \\
Category III & $0(0.00)$ & $3(2.13)$ & \\
No & $6(66.67)$ & $101(71.63)$ & \\
Not stated & $1(11.11)$ & $1(0.71)$ & \\
\hline Ultrasound & & & \\
Category I & $1(11.11)$ & $35(24.82)$ & \\
Categories I and II & $0(0.00)$ & $1(0.71)$ & \\
Category II & $0(0.00)$ & $1(0.71)$ & 0.96 \\
Category III & $0(0.00)$ & $2(1.72)$ & \\
No & $8(88.89)$ & $101(71.63)$ & \\
Not stated & $0(0.00)$ & $1(0.71)$ & \\
\hline
\end{tabular}

TABLE 5: Relationship between comorbidities, previous history of cancer, presence of breast nodules, family history of breast cancer and other types of cancer, and açaí consumption among women residing in the Maracanã neighborhood, São Luís, MA.

\begin{tabular}{|c|c|c|c|}
\hline \multirow{2}{*}{ Variables } & \multicolumn{2}{|c|}{ Açaí consumption } & \multirow[b]{2}{*}{$p$} \\
\hline & No $f(\%)$ & Yes $f(\%)$ & \\
\hline \multicolumn{4}{|c|}{ Family history of breast cancer** } \\
\hline No & $9(100.00)$ & $130(92.20)$ & \multirow[t]{2}{*}{0.62} \\
\hline Yes & $0(0.00)$ & $11(7.80)$ & \\
\hline \multicolumn{4}{|c|}{ Other types of cancer in the family** } \\
\hline No & $6(66.67)$ & $110(78.01)$ & \multirow[t]{2}{*}{0.43} \\
\hline Yes & $3(33.33)$ & $31(21.99)$ & \\
\hline \multicolumn{4}{|c|}{ Previous history of cancer** } \\
\hline No & $9(100.00)$ & $139(98.58)$ & \multirow[t]{2}{*}{0.71} \\
\hline Yes & $0(0.00)$ & $2(1.42)$ & \\
\hline \multicolumn{4}{|l|}{ Nodule** } \\
\hline No & $9(100.00)$ & $130(92.20)$ & \multirow[t]{2}{*}{0.38} \\
\hline Yes & $0(0.00)$ & $11(7.80)$ & \\
\hline \multicolumn{4}{|l|}{ Diabetes* } \\
\hline Yes & $1(11.11)$ & $19(13.47)$ & \multirow{3}{*}{0.91} \\
\hline No & $8(88.89)$ & $120(85.11)$ & \\
\hline Not stated & $0(0.00)$ & $2(1.42)$ & \\
\hline \multicolumn{4}{|c|}{ Heart disease $^{* *}$} \\
\hline Yes & $0(0.00)$ & $10(7.09)$ & \multirow[t]{2}{*}{0.52} \\
\hline No & $9(100.00)$ & $131(92.91)$ & \\
\hline \multicolumn{4}{|c|}{ Hypertension* } \\
\hline Yes & $3(33.33)$ & $31(21.98)$ & \multirow{3}{*}{0.96} \\
\hline No & $6(66.67)$ & $105(74.47)$ & \\
\hline Not stated & $0(0.00)$ & $5(3.55)$ & \\
\hline
\end{tabular}

${ }^{*}$ Chi-square test. ${ }^{* *}$ Fisher's exact test.

The high antioxidant capacity of açaí has been confirmed in several in vitro studies. Moreover, açaí was shown to have a higher antioxidant capacity than that of other fruits with antioxidant potential, including cranberries, blueberries, and strawberries. The antioxidant activity of açaí supplementation has been examined in in vivo studies conducted with mice. After six weeks of açaí consumption, there was an increase in the antioxidant activity of paraoxonase 1 (PON-
1) in rats that received normal or cholesterol-enriched diets [17].

Epidemiological studies and systematic analyses suggest that diets rich in fruits and vegetables are associated with a reduction in the risk of developing cancer, especially cancers of epithelial origin such as mouth, colon, rectum, lung, and breast cancers [16]. However, in the case of chronic diseases, because it takes a long time (usually decades) for symptoms to manifest and because of the lack of animal models, epidemiological studies have been the key tool for establishing associations between the intake of food components and its subsequent effects on health [18].

Therefore, the objective of the present study was to analyze the relationship between açaí consumption and chronic diseases. For this purpose, a survey was conducted to collect data to assess this relationship. The results showed a high prevalence of açaí consumption among the women in the sample $(94.00 \% ; 141 / 150)$, most of which $(77.30 \%$ or 109/141) had consumed açaí for more than 10 years. Despite this habit, there were no statistically significant differences relative to the control group $(6.00 \% ; 9 / 150)$ with regard to comorbidities, previous history of cancer, family history of cancer, changes in imaging exams (mammography and breast ultrasound), and presence of breast nodules. The prevalence of comorbidities among the açaí consumers was higher than that among the nonconsumers (with the exception of the prevalence of hypertension, which was higher in the group of nonconsumers). Breast cancer was the second most prevalent type of cancer included in the family history of cancer. In fact, several experimental studies have evaluated the effects of flavonoids present in extracts of açaí and other fruits on breast cancer cells $[5,7,16,19]$.

Our study evidenced a tendency of açaí to reduce diabetes and hypertension in women.

Açaí is rich in polyphenols that have some antidiabetic effects [20]. They can induce satiety, modulate the digestive processes and carbohydrate absorption, and modulate hormonal processes related to sugar intake [21-23].

de Bem et al. evidenced that association of exercise and the açaí seed extract in rats improved diabetic complications. Açaí reduced blood glucose, insulin resistance, leptin and IL6 levels, lipid profile, and vascular dysfunction [24].

Regarding antihypertensive effects of açaí, da Costa et al. evidenced that administration of the açaí seed extract $(200 \mathrm{mg} / \mathrm{kg})$ increased systolic blood pressure, decreased urea and creatinine levels, and prevented oxidative damage in animals [25].

Polyphenols from the seed of acai increase endothelial nitric oxide production leading to endothelium-dependent relaxation, reduction of reactive oxygen species, and regulation of key targets in hypertension [26].

This study is the first study to correlate the açaii intake and chronic disease prevention in São Luís, MA, Brazil. The sample size was not too great, and a small control group could be difficult for statistical analysis; the results were not significant.

Thus, studies on the relationship between the intake of fruits and vegetables rich in flavonoids and the risk of developing chronic diseases, including cancer, are of great 
value for the international literature and for the advancement of cancer treatment and prevention, especially in the case of cancers that are more prevalent and associated with higher morbidity, such as breast cancer in Brazil and worldwide. Further studies need to be performed to evaluate the relationship between açaí intake and chronic diseases.

\section{Data Availability}

All data are included in the manuscript.

\section{Conflicts of Interest}

The authors declare that they do not have any conflicts of interest.

\section{Authors' Contributions}

DFS and MDSBN designed the research; DFS, MACN, FCBV, WEMF, GFBB, GMR, KRAB, and MDSBN conducted the research; DFS, MACNS, GMR, LMOB, MCLB, JEC, and MDSBN were involved in data analysis and statistical analysis. All authors have read and agreed with the manuscript.

\section{Acknowledgments}

This study was supported by the Foundation for the Support of Research and Scientific and Technological Development of Maranhão (FAPEMA)-Ed. Universal.

\section{References}

[1] J. A. Portinho, L. M. Zimmermann, and M. R. Bruck, "Efeitos benéficos do açai," International Journal of Nutrology, vol. 5, no. $1,2012$.

[2] A. M. Figueiredo and I. R. C. Biernet, "Assessment of the scientific evidence of the potential use of açai (Euterpe oleracea, Mart.) in clinical outcomes: analysis with focus on antioxidant and anti-inflammatory action," International Journal of Nutrology, vol. 7, no. 2, 2014.

[3] V. Mulabagal, W. J. Keller, and A. I. Calderón, "Quantitative analysis of anthocyanins in Euterpe oleracea (açaí) dietary supplement raw materials and capsules by Q-TOF liquid chromatography/mass spectrometry," Pharmaceutical Biology, vol. 50, no. 10, pp. 1289-1296, 2012.

[4] K. H. Kwon, A. Barve, S. Yu, M.-T. Huang, and A.-N. T. Kong, "Cancer chemoprevention by phytochemicals: potential molecular targets, biomarkers and animal models," Acta Pharmacologica Sinica, vol. 28, no. 9, pp. 1409-1421, 2007.

[5] D. F. Silva, Análise da citotoxicidade do extrato de juçara (Euterpe oleracea Mart.) do Maranhão em células malignas humanas. 2013. 101 f. Tese (Doutorado)_Curso de Programa de Pós-graduação em Fisiopatologia Clínica e Experimental, Universidade Estadual do Rio de Janeiro, Rio de Janeiro, Brazil, 2013.

[6] Instituto Nacional de Câncer José Alencar Gomes da Silva, Coordenação Geral de Ações Estratégicas. Coordenação de Prevenção e Vigilância, INCA, Rio de Janeiro, Brazil, 2016.

[7] C. Hui, X. Qi, Z. Qianyong, P. Xiaoli, Z. Jundong, and M. Mantian, "Flavonoids, flavonoid subclasses and breast cancer risk: a meta-analysis of epidemiologic studies," PLoS One, vol. 8, no. 1, Article ID e54318, 2013.

[8] S. Mohanty and I. E. Cock, "The chemotherapeutic potential of Terminalia ferdinandiana: phytochemistry and bioactivity," Pharmacognosy Reviews, vol. 6, no. 6, pp. 29-36, 2012.

[9] P. Liedo, J. R. Carey, D. K. Ingram, and S. Zou, "The interplay among dietary fat, sugar, protein and Açai (Euterpe oleracea Mart.) pulp in modulating lifespan and reproduction in a Tephritid fruit fly," Experimental Gerontology, vol. 47, no. 7, pp. 536-539, 2012.

[10] M. Laslo, X. Sun, C.-T. Hsiao, W. W. Wu, R.-F. Shen, and S. Zou, "A botanical containing freeze dried Açai pulp promotes healthy aging and reduces oxidative damage in sod1 knockdown flies," Age, vol. 35, no. 4, pp. 1117-1132, 2013.

[11] A. C. Feitosa and J. R. Trovão, Atlas escolar do Maranhão: Espaço Geo-Historico e Cultural, Grafset, João Pessoa, Brazil, 2006.

[12] J. K. Udani, B. B. Singh, and V. J. Singh, "Effects of Açai (Euterpe oleracea Mart.) berry preparation on metabolic parameters in a healthy overweight population: a pilot study," Nutrition Journal, vol. 10, no. 1, p. 45, 2011.

[13] A. Cassidy, É. J. O’Reilly, C. Kay et al., "Habitual intake of flavonoid subclasses and incident hypertension in adults," The American Journal of Clinical Nutrition, vol. 93, no. 2, pp. 338-347, 2011.

[14] B. B. G. Calzavara, “As possibilidades do açaizeiro no estuário amazônico. Boletim da faculdade de ciências agrárias do pará," Belém, vol. 5, pp. 1-103, 1972.

[15] H. Villachica, J. E. U. Carvalho, C. H. Müller, S. C. Diaz, and M. Almanza, Frutales y hortalizas promissorios de la Amazonia, Tratado de Cooperacción Amazonica, Lima, Peru, 1996.

[16] L. Cui, X. Liu, Y. Tian et al., "Flavonoids, flavonoid subclasses, and esophageal cancer risk: a meta-analysis of epidemiologic studies," Nutrients, vol. 8, no. 6, p. 350, 2016.

[17] D. Pala, P. O. Barbosa, C. T. Silva et al., "Açai (Euterpe oleracea Mart.) dietary intake affects plasma lipids, apolipoproteins, cholesteryl ester transfer to high-density lipoprotein and redox metabolism: a prospective study in women," Clinical Nutrition, vol. 37, no. 2, pp. 618-623, 2018.

[18] G. R. Beecher, "Overview of dietary flavonoids: nomenclature, occurrence and intake," The Journal of Nutrition, vol. 133, no. 10, pp. 3248S-3254S, 2003.

[19] Q.-H. Wang, S. Guo, X.-Y. Yang et al., "Flavonoids isolated from Sinopodophylli fructus and their bioactivities against human breast cancer cells," Chinese Journal of Natural Medicines, vol. 15, no. 3, pp. 225-233, 2017.

[20] J. A. Domínguez Avila, J. Rodrigo García, G. A. González Aguilar, and L. A. de la Rosa, "The antidiabetic mechanisms of polyphenols related to increased glucagon-like peptide1(GLP1) and Insulin signaling," Molecules, vol. 22, no. 6, 2017.

[21] H. Nyambe-Silavwe and G. Williamson, "Polyphenol- and fibre-rich dried fruits with green tea attenuate starch-derived postprandial blood glucose and insulin: a randomised, controlled, single-blind, cross-over intervention," British Journal of Nutrition, vol. 116, no. 3, pp. 443-450, 2016.

[22] C. L. Campbell, E. A. Foegeding, and G. K. Harris, "Cocoa and whey protein differentially affect markers of lipid and glucose metabolism and satiety," Journal of Medicinal Food, vol. 19, no. 3, pp. 219-227, 2016.

[23] I. Grzegorczyk-Karolak, K. Gołąb, J. Gburek, H. Wysokińska, and A. Matkowski, "Inhibition of advanced glycation endproduct formation and antioxidant activity by extracts and polyphenols from Scutellaria alpina L. and S. Altissima L." Molecules, vol. 21, no. 6, 2016. 
[24] G. F. de Bem, C. A. Costa, I. B. Santos et al., "Antidiabetic effect of Euterpe oleracea Mart. (açaí) extract and exercise training on high-fat diet and streptozotocin-induced diabetic rats: a positive interaction," PLoS One, vol. 13, no. 6, Article ID e0199207, 201819.

[25] C. A. da Costa, D. T. Ognibene, V. S. C. Cordeiro et al., "Effect of Euterpe oleracea Mart. Seeds extract on chronic ischemic renal injury in renovascular hypertensive rats," Journal of Medicinal Food, vol. 20, no. 10, pp. 1002-1010, 2017.

[26] R. S. de Moura and Â. C. Resende, "Cardiovascular and metabolic effects of açaí, an amazon plant," Journal of Cardiovascular Pharmacology, vol. 68, no. 1, pp. 19-26, 2016. 